\title{
Identification of a Degrading-Bacterium SG-2 and Preparing Complex Microbial Community for Degrading Chlorpyrifos
}

\author{
Liu Zhiyuan ${ }^{1, \text { a }}$ \\ ${ }^{1}$ Department of environmental engineering,Shenyang Institute of Technology,Fushun \\ 113122, China
}

a54105222@163.com

\begin{abstract}
Keywords: Chlorpyrifos, Bacillus sp., compound bacterium agent
Abstract. A bacterium capable of degrading chlorpyrifos named SG-2 was isolated from the corn soil in Shenyang Institute of Technology, Northeast China. The bacterium SG-2 was identified as Bacillus sp., according to its morphological, physiological characteristics and the phylogenetic analysis of 16S-rRNA. A compound bacterium agent compound of SG-2 and Cunninghamella about the ability of degrading chlorpyrifos was prepared in this study. Incubation tests showed that the initial concentration of chlorpyrifos in culture was $100 \mathrm{mg} \mathrm{L}^{-1}$, incubation for $48 \mathrm{~h}$ at $30{ }^{\circ} \mathrm{C}$, the degrading rate of chlorpyrifos of SG-2, Cunninghamella and the compound bacterium agent were $65.12 \%$, $56.36 \%$ and $83.71 \%$, respectively. Further study should be conducted to investigate the degradation pathways of chlorpyrifos by bacteria SG-2 and the compound bacterium agent and the optimal conditions of the degradation in the soil system.
\end{abstract}

\section{Introduction}

Chlorpyrifos, the effective chemical composition is O,O-diethyl O-(3,5,6-trichloro-2-pyridyl) phosphorothioate[1], Since being developed in 1965, it has been widely used to control 90 species insects of agriculture, fruit, vegetable, flowers, grazier, sanitation and so on. Chlorpyrifos has highly effective, fast, low poisonous remains lowly and so on characteristics, has both the contact and stomach function, has the very good control efficiency to the snout moth's larva,leaf folder,oriental armyworm,scale insect, aphid,cotton bollworm,leafhopper and mite. Chlorpyrifos is one of the most widely used organophosphate insecticides in China in these years and could substitute highly poisonous methamidophos,parathion and parathion-methyl. But it widespread use has caused severe environmental pollution and threated human health. Therefore, how to isolated a high efficient organophosphorus pesticide degrading bacteria and to study their degradation properties is a need to be resolved and the research is of great significance in the current social environment.

This paper report the use of complex microbial agents to remove pesticide residues test results, the work done in this paper provides the theoretic and test evidences for further exploration the technology of biodegradation of organophosphate pesticides and bioremediation of polluted water and soil.

\section{Materials and Methods}

Soil enrichment technique

Soil used for the isolated of chlorpyrifos-degrading bacteria was obtained from the farm of in Shenyang Institute of Technology, China. The soil sample was taken from the top $20 \mathrm{~cm}$ of the field by the method of five-point random sampling, removed the stone and plant residue and passed through a sieve with $2 \mathrm{~mm}$ mesh. The soil sample was taken with an aqueous suspension of chlorpyrifos to give a final concentration of $100 \mathrm{mg} \mathrm{kg}^{-1}$ in soil and incubated it at $30^{\circ} \mathrm{C}$ for 2 weeks. The moisture content of the soil was kept constant by adding distilled water (50\%) every two days to obtain their original weight. 
Isolation and identification of Chlorpyrifos degrading bacteria

Chlorpyrifos degrading bacteria was isolated by the enrichment culture technique. $1 \mathrm{~g}$ soil sample was added into a $250 \mathrm{~mL}$ flask with $100 \mathrm{ml}$ selective media, which the final concentration of chlorpyrifos was $50 \mathrm{mg} \mathrm{L}^{-1}$. The culture was incubated at $30^{\mathrm{C}}, 120 \mathrm{rpm}$ for $72 \mathrm{~h}$. Then $10 \mathrm{~mL}$ of the enrichment culture was transferred into a new $250 \mathrm{ml}$ flask with fresh $90 \mathrm{ml}$ selective media, which the final concentration of chlorpyrifos was $100 \mathrm{mg} \mathrm{L}^{-1}$. The inoculation conditions was the same as before. $10 \mathrm{~mL}$ of the culture solution was subcultured into $90 \mathrm{~mL}$ fresh selective media every $72 \mathrm{~h}$ until the final concentration of chlorpyrifos reached $250 \mathrm{mg} \mathrm{L}^{-1}$. The enriched culture was 10times echelon diluted and spread on selective media plates containing $1.5 \%-2 \%(\mathrm{~W} / \mathrm{V})$ purified agar. After $3 \mathrm{~d}$ incubated at $30 \mathrm{c}$, bacteria colonies were visible. Microorganism were randomly selected and inoculated to a LB media at $30^{\mathrm{c}}$ for $16 \mathrm{~h}$, then subcultured the bacteria suspension into a fresh selective media at $30^{\mathrm{C}}$ for 2 days. Gas chromatographic (GC) was used to detect the chlorpyrifos residues and confirm the degrading-bacteria.

\section{Media}

Three different media, a mineral salt medium (MSM), a selective media and an enriched medium, were used in both enrichment soil sample and liquid culture of isolated bacteria.The mineral salt medium (MSM, pH 7.0) containing ( $\left.\mathrm{g} \mathrm{L}^{-1}\right) \mathrm{K}_{2} \mathrm{HPO}_{4}, 10.5 ; \mathrm{KH}_{2} \mathrm{PO}_{4}, 4.5 ;\left(\mathrm{NH}_{4}\right)_{2} \mathrm{SO}_{4}, 1.0$; $\mathrm{NaCl}, 1.0$ was used in this research. The selective media (1L) containing $1000 \mathrm{~mL}$ MSM with $100 \mathrm{mg}$ chlorpyrifos. The Luria-Bertani medium ( $\mathrm{pH}$ 7.0-7.2) containing $\left(\mathrm{g} \mathrm{L}^{-1}\right)$ tryptone 10.0; yeast extract $5.0 ; \mathrm{NaCl}, 10.0$ was used for enrich the degradation-bacteria.

\section{Taxonomic identification}

Identification of chlorpyrifos degrading -bacteria was based on morphological, physiological and biochemical test according to Bergey's Manual of Determinative Bacteriology [2] and combined with analysis sequencing of the 16S-rRNA gene. The total genomic DNA was extracted from the degrading -bacteria by the method of a standard phenolic extraction procedure[3]. The 16S-rRNA gene was amplified by polymerase chain reaction (PCR) using standard procedures with the universal primer of 8f (5'AGAGTTTGATCCTGGCTCA-3') and 1492r (5'-GCTTACCTTGTT ACGACRTT-3'). The conditions for PCR were as follow: initial denaturation at $94 \mathrm{C}$ for $5 \mathrm{~min}$, followed by 30 cycles of denaturation $94^{\circ} \mathrm{C}$ for $1 \mathrm{~min}$, annealing at $55^{\circ} \mathrm{C}$ for $1 \mathrm{~min}$, at $72^{\mathrm{C}}$ for for $1.5 \mathrm{~min}$, and final extension at $72^{\mathrm{C}}$ for $8 \mathrm{~min}$ [4]. Ligated the PCR product into the vector pMD-18T and then transformed it into E. coil DH5 $\alpha$ to determine the gene sequence of 16S-rRNA. Compared the determined sequence of 16S-rRNA( $1569 \mathrm{bp}$ in length ) with those available in the GenBank database with the NCBI blast program. Unrooted tree were built using the neighbor joining method [5]. Each dataset was bootstrapped 1000 times.

\section{Preparation of the mixed bacteria species}

The fungus of Cunninghamella was supplied by Institute of Applied Ecology, Chinese Academy of Sciences and the degrading-bacteria was isolated by the environmental laboratory of Shenyang Institute of Technology. Inoculated the Cunninghamella in the middle of the AGAR plate and the degrading-bacteria SG-2 in the four corners. Cultured at $28 \mathrm{c}$ for 3 days, then measured the bacteriostat distance, selected the degrading-bacteria no antagonistic effect to prepared the mixed bacteria species[6]. 
gas chromatographic analysis of chlorpyrifos

For the determination of chlorpyrifos pesticides, all samples were analyzed according GBGB/T14552-2003 and measured by gas chromatographic (GC). The analysis conditions as follow: chromatographic column,DB-1701 $(30 \mathrm{~mm} \times 0.25 \mathrm{~mm} \times 0.25 \mu \mathrm{m})$; the injection port temperature was $240 \mathrm{C}$; and the temperature for the ECD detector was $300^{\mathrm{C}}$; temperature program: $150 \mathrm{C}$ for $2 \mathrm{~min}$, headed to $260^{\mathrm{C}}$ at the heating rate $5^{\mathrm{C}} \cdot \mathrm{min}^{-1}$, the final temperature was kept for 6 min. Injection Volume was $1 \mu \mathrm{L}$; Injection mode: split-less injection[7].

\section{Result and discussion}

Isolation and identification of the degrading-beacteria SG-2

From the soil samples, two kinds of chlorpyrifos degrading-bacteria were isolated by the enrichment procedure. One of them named SG-2 showed a higher degrading capability and selected for further study.The strains clone of the bacteria SG-2 was a circular depression, bacillus, have spore, skin-dried, translucent, the edge was smooth, the color was creamy. It was positive in tests for Gram staining, gelatin hydrolysis, methyl red test, V.P test and citrate utilization test, but negative for starch hydrolysate, urea test and indole test.

The 16S-rDNA sequence sequence of SG-2 was obtained, and it demonstrated high similarity to the 16S-rDNA sequence from members of the genus Bacillus species.A phylogenetic tree based on the 16S-rDNA gene sequence of SG-2 was constructed (Fig.1) Base on the characters, degrading-bacteria SG-2 was preliminarily identified as Bacillus.

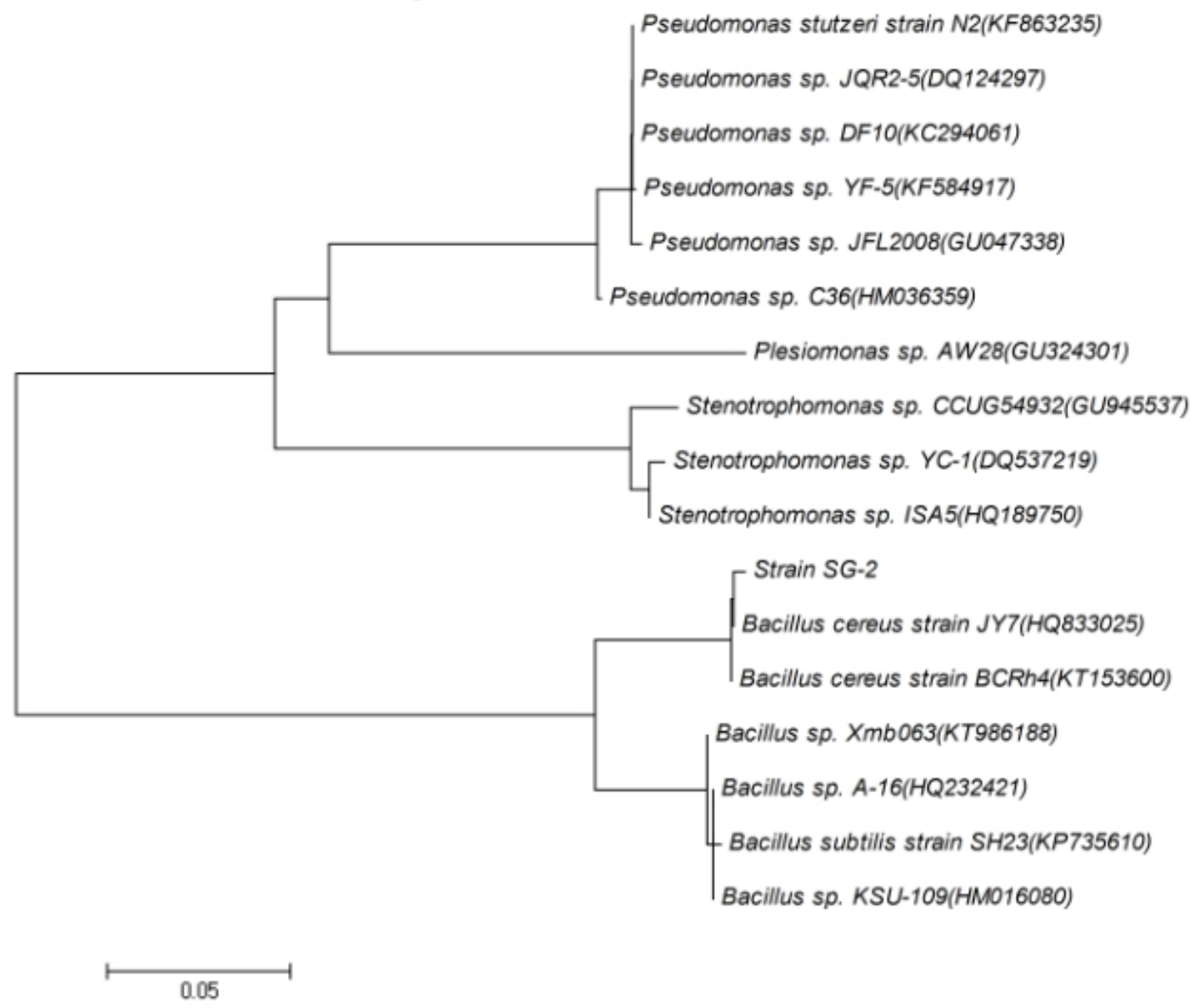

Fig.1 Phylogenetic tree of strain SG-2 base on 16S rRNA gene sequence analysis. 
Prepared of the compound bacterium agent

Observed the antagonist effects of Cunninghamella and the degrading-bacteria SG-2 according to the streak plate method. Simulation result shows that 2 strains have no inhibiting effects on one another which can prepare the compound bacterium agent for bacteriostat distance of the two strains is 0.9 $\mathrm{mm}$. Compound the bacterium agent in proportion of 1 to 1 [6], after centrifugation the supernatant was discarded and prepared to organism suspension using the remainder at the rate of 1:10, the absorbance of the organism suspension is OD560 $=0.906$.

\section{Degradation of chlorpyrifos in cell culture}

The time course of chlorpyrifos degradation by the bacterium agent(degrading-bacteria SG-2, Cunninghamella and the compound bacterium agent) in the selective media is presented in Fig.1. All the degradation studies were carried out at $30^{\mathrm{C}}, 150 \mathrm{rpm}$ in media supplemented with $100 \mathrm{mg} \cdot \mathrm{L}-1$ chlorpyrifos for $48 \mathrm{~h}$. Culture were sampled every $6 \mathrm{~h}$ and checked for chlorpyrifos residues to calculate the degradation rate. Culture were ran in triplicate to ensure accuracy. The selective media without inoculation was used as controls. The result indicated that the removal rate of chlorpyrifos in the control was quite low during $48 \mathrm{~h}$ in the condition of abundant sunlight and oxygen. Therefore, we can still draw a conclusion that sunlight and oxygen have the effect to degradation of chlorpyrifos, but it has a limited effect on the degradation. All these bacterium agent in varying degrees impact the degradation of chlorpyrifos, the degradation rate of degrading-bacteria SG-2, Cunninghamella and the compound bacterium agent were $65.12 \%, 56.36 \%$ and $83.71 \%$, respectively. The degradation rate of the compound bacterium agent was higher than degrading-bacteria SG-2 and Cunninghamella, obviously.

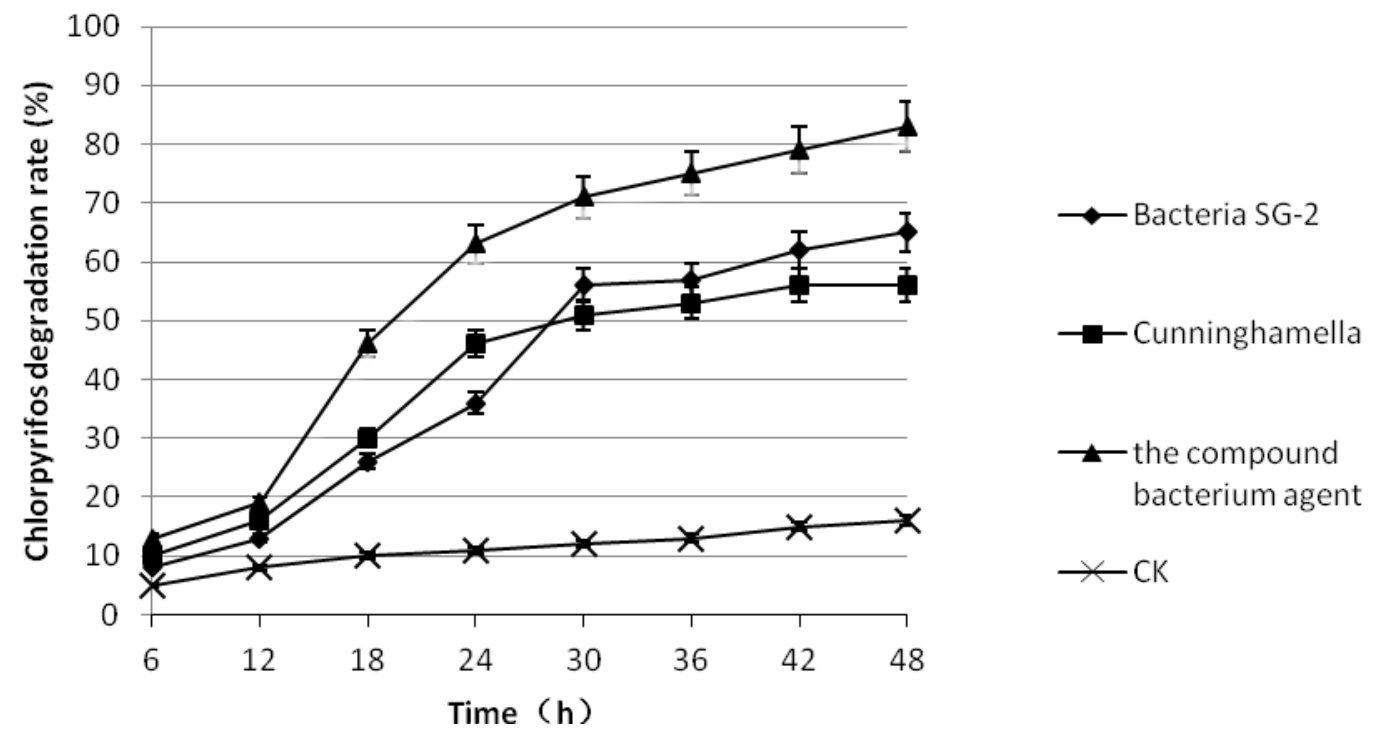

Fig.2 degradation of chlorpyrifos in liquid culture

\section{Conclusions}

So far, there has rare report about compound bacterium agent about the ability of degrading chlorpyrifos. The bacteria SG-2 isolated from the chlorpyrifos polluted soil samples which could be the single energy resources to degrading the chlorpyrifos. The strain SG-2 was showed similarity to members of the genus Bacillus species. Incubation tests showed that the initial concentration of chlorpyrifos in culture was $100 \mathrm{mg} \mathrm{L}^{-1}$, SG-2 could degrade the chlorpyrifos the degrading rate can reach $65 \%$ after incubation for $48 \mathrm{~h}$. The degrading rate of the Cunninghamella and the compound 
bacterium agent were $56.36 \%$ and $83.71 \%$, respectively. Further study should be conducted to investigate the degradation pathways of chlorpyrifos by bacteria SG-2 and the compound bacterium agent and the optimal conditions of the degradation in the soil system.

\section{Acknowledgements}

This work was financially supported by the Shenyang Institute of Technology Dr. startup fund (No. BS201405) .

\section{References}

[1] L.Xiaohui, H.Jianhe and L.Shenpeng: Isolation of a chlorpyrifos-degrading bacterium, Sphingomonas sp. strain Dsp-2, and cloning of the mpd gene. Research in Microbiology Vol.158.2 (2007),p.143-149.

[2] R.E. Buchanan and N.E. Gibbons:Bergey's manual of determinative bacteriology(Baltimore : Williams \& Wilkins Publications, United States 1974)

[3] J Sanbrook, EF Fritsch: Molecular cloning: a laboratory manual,2nd edn (Coldspring -Harbour Laboratory Press Publications, United States 1989)

[4] C Yang, N Liu, X Guo, C Qiao: Cloning of mpd gene from a chlorpyrifos-degrading bacterium and use of this strain in bioremediation of contaminated soil.FEMS microbiology letters Vol 265.1 (2006),p. 118-125.

[5] N.Saitou, M.Nei, The neighbor-joining-method: a new method for reconstructing phylogenetic trees. Molecular biology and evolution, Vol 4.4(1987),p. 406-425.

[6] N. Mingfen, L.Zhiyuan, L.Zhouping: Preparating and Researching the Efficient Comple Microbial Community for Degradating Chlorpyrifos. J. Agro-Environ. Sci. Vol.29.2(2010),p. 381- 385

[7] N. Mengfen, L. Zhiyuan, C.Wei, et al. The Bio-remediation Technology of Organophosphorus Pesticides Contaminated Soil.Digital Manufacturing and Automation (ICDMA), 2011 Second International Conference IEEE, (2011),p.1217-1220. 